OPEN ACCESS

Edited by:

Ralf Jockers,

Université Paris-Sorbonne, France

Reviewed by:

Xin Cui,

Georgia State University,

United States

Yasuo Shinohara

Tokushima University, Japan

*Correspondence:

Rivka Dresner-Pollak

rivkap@hadassah.org.il

†These authors have contributed equally to this work

${ }^{\ddagger}$ Present Address:

Einav Cohen-Kfir,

Institute of Medical Research

Israel-Canada, Hebrew

University-Hadassah Medical School,

Jerusalem, Israel

Specialty section:

This article was submitted to

Cellular Endocrinology,

a section of the journal

Frontiers in Endocrinology

Received: 31 July 2018 Accepted: 11 February 2019

Published: 28 February 2019

Citation:

Artsi H, Gurt I, El-Haj M, Müller $R$,

Kuhn GA, Ben Shalom $G$, Cohen-Kfir E, Abramowitz E, Kandel L, Safran O and Dresner-Pollak R (2019) Sirt1 Promotes a Thermogenic Gene Program in Bone Marrow Adipocytes:

From Mice to (Wo)Men

Front. Endocrinol. 10:126.

doi: 10.3389/fendo.2019.00126

\section{Sirt1 Promotes a Thermogenic Gene Program in Bone Marrow Adipocytes: From Mice to (Wo)Men}

\author{
Hanna Artsi ${ }^{1+}$, Irina Gurt ${ }^{1 \dagger}$, Madi El-Haj ${ }^{2}$, Ralph Müller ${ }^{3}$, Gisela A. Kuhn ${ }^{3}$, \\ Gal Ben Shalom ${ }^{1}$, Einav Cohen-Kfir ${ }^{1 \neq}$, Eva Abramowitz ${ }^{1}$, Leonid Kandel ${ }^{2}$, Ori Safran ${ }^{2}$ and \\ Rivka Dresner-Pollak ${ }^{1 *}$ \\ ${ }^{1}$ Division of Medicine, Department of Endocrinology and Metabolism, Faculty of Medicine, The Hadassah Medical Center, \\ Hebrew University of Jerusalem, Jerusalem, Israel, ${ }^{2}$ Department of Orthopedics, Faculty of Medicine, The Hadassah Medical \\ Center, Hebrew University of Jerusalem, Jerusalem, Israel, ${ }^{3}$ Department of Health Sciences and Technology, Institute for \\ Biomechanics, ETH Zurich, Zurich, Switzerland
}

Bone marrow adipose tissue (MAT) is influenced by nutritional cues, and participates in whole body energy metabolism. To investigate the role of Sirtuin1 (Sirt1), a key player in metabolism, in MAT, marrow adiposity was evaluated in inbred 5-month-old 129/Sv Sirt1 haplo-insufficient $\left(\operatorname{Sirt}^{\Delta /+}\right)$ and wild type (WT) mice. Decreased expression of the thermogenic genes: Prdm16, Pgc1 $\alpha$, Foxc2, Dio2, and $\beta 3 A R$ was detected in whole tibiae derived from $\operatorname{Sirt}^{\Delta /+}$ compared to WT female mice. Similarly, decreased expression of Prdm16 and Pgc1 $\alpha$ was observed in primary bone marrow mesenchymal stem cell (BM-MSC) cultures obtained from Sirt1 ${ }^{\Delta /+}$ compared to WT female mice, suggesting a cell autonomous effect of Sirt1 in BM-MSCs. In vitro, Sirt1 over-expression in the mesenchymal embryonic fibroblast stem cell line C3HT101/2 increased Pgc1a and Prdm16 protein level. Similarly, pharmacologic activation of Sirt1 by SRT3025 increased Foxc2, Pgc1 1 , Dio2, Tfam, and Cyc1 expression while inhibition of Sirt1 by EX527 down-regulated UCP1 in C3HT101/2 cells. Importantly, in human femoral BM-MSCs obtained from female patients undergoing hip operations for fracture or osteoarthritis, Sirt1 activation by SRT3025 increased PGC1 $\alpha$ mRNA and protein level. Blocking sclerostin, an inhibitor of the WNT pathway and a Sirt1 target, by the monoclonal humanized antibody (Sc-AbIl), stimulated $\beta 3 A R$, PRDM16, and UCP1 gene expression, and increased PGC1 $\alpha$ protein level. These results show that Sirt1 stimulates a thermogenic gene program in marrow adipocytes in mice and humans via PGC1 $\alpha$ activation and sclerostin inhibition. The implications of these findings to bone health, hematopoiesis and whole body energy metabolism remain to be investigated. Keywords: sirtuin1, marrow adipose tissue, PGC1-alpha, bone marrow mesenchymal stem cells,
thermogenic genes

\section{INTRODUCTION}

Adipose tissue consists of three main fat depots: visceral, subcutaneous, and marrow. Marrow adipose tissue (MAT) was initially thought to be metabolically inert and a filler only. Recent studies however have found that MAT responds to nutritional cues and exercise, and participates in whole body fat metabolism (1-4). Studies in mice and humans undergoing bone 
marrow transplantation have demonstrated trafficking of bone marrow (BM)-derived circulating progenitor cells to adipose tissue, their differentiation into subcutaneous adipocytes and increased representation in obesity $(5,6)$. Furthermore, MAT was shown to contribute to circulating adiponectin in mice subjected to calorie restriction and in humans undergoing anticancer therapy (1). Interestingly, MAT response to nutritional cues can be distinct than visceral and subcutaneous fat depots. Calorie restriction, anti-cancer therapy, type 1 diabetes mellitus and anorexia nervosa all lead to peripheral fat loss but are surprisingly associated with increased MAT volume (7). In addition, MAT volume is inversely related to bone mass and strength in postmenopausal osteoporosis, aging and glucocorticoid excess (8-11). Finally, marrow adipocytes negatively regulate hematopoiesis and support bone homing cancers $(12,13)$. Thus, elucidating the mechanisms that regulate MAT may reveal novel pathways that influence bone turnover, hematopoiesis and whole body energy metabolism.

Three types of adipocytes reside in fat depots: white, brown, and beige. Lipid rich white adipocytes expand with energy intake and store triglycerides. Mitochondria rich brown adipocyte arise from a muscle-like cell lineage $\left(M y f 5^{+}\right)$and dissipate energy as heat, while beige adipocytes (brite) emerge in white fat depots, bear characteristics of brown adipocytes, but do not originate from the $M y f 5^{+}$lineage (14).

The origin of bone marrow adipocytes is still unknown, and tools to genetically manipulate it are limited. The prevailing model suggests that a self-renewing bone marrow (BM) mesenchymal stem cell (BM-MSC) exists within the bone marrow that gives rise to osteoblasts, adipocytes, chondrocytes and marrow stromal cells (15). This BM-MSC was identified as the bone marrow stromal stem cell (BMSC) that surrounds bone marrow sinusoids (16), and has in vivo osteogenic and adipogenic potential. The regulatory factors that are involved in BMSC commitment to the adipocyte lineage are starting to unravel. BMSCs that express the leptin receptor (LepR) have the capacity to differentiate into both adipocytes and osteoblasts, while LepR is not expressed by neither mature osteoblasts nor marrow adipocytes, suggesting that LepR in BMSCs influences lineage allocation (17). Consistently, Leptin signaling via the LepR induced by high-fat-diet failed to promote marrow adipogenesis in mice with LepR deletion in BMSCs but not in osteoblasts, confirming that the effect is restricted to BMSCs (18). Another hormonal pathway affecting the BMSC fate is the parathyroid hormone/parathyroid hormone related peptide (PTH/PTHrP) receptor signaling pathway. Genetic loss $\mathrm{PTH} / \mathrm{PTHrP}$ receptor (PTH1R) in mesenchymal stem cells using the paired related homeobox transcription factor 1 (Prx1)-Cre driver was reported to induce marrow adipogenesis, while PTH administration reduced marrow fat in mice and male patients with idiopathic osteoporosis, suggesting that PTH inhibits the differentiation of adipocyte progenitors to the adipocyte lineage (19). On another level of complexity, region-specific variation in MAT development, regulation and phenotype was reported in mice, rats and humans (20).

Sirtuin1 (Sirt1), a member of the sirtuin family of $\mathrm{NAD}^{+}$. dependent protein deacetylases, is a key cellular energy sensor and a mediator of the beneficial effects of calorie restriction in some animal models (21). Sirtl regulates glucose and fat metabolism $(22,23)$. In vitro, Sirt1 inhibited the generation of white adipocytes in 3T3L-1 pre-adipocytes by down-regulating Ppar $\gamma$, a master gene in white adipocytes differentiation (24). In vivo, adipose selective over-expression of a dominant negative Sirt1 resulted in dyslipidemia and ectopic lipid deposition (25). Targeted Sirt1 deficiency in mature adipocytes accelerated the onset of obesity-induced insulin resistance and glucose intolerance (26). On the other hand, Sirtl gain-of-function induced a brown adipocyte-like phenotype in white adipocytes by deacetylating Ppar $\gamma$ and modulating its transcriptional activity (27).

Others and we have previously reported that Sirt1 directly regulates bone osteoblasts, osteoclasts and osteocytes (28-33). However, the role of Sirt1 in MAT is still largely unknown. In vitro, Sirt1 and its pharmacologic activation decreased adipogenesis of bone marrow MSCs (34-36). MSC-specific Sirt1 knock-out mice using the Prx1-Cre driver (MSCKO mice) exhibited reduced subcutaneous fat with aging, but no significant change in marrow adipocyte size compared to young mice (37).

Marrow adipogenesis is influenced by the WNT signaling pathway $(38,39)$. We have previously reported that Sirt1 is a negative regulator of sclerostin, an inhibitor of the canonical WNT pathway in bone (28). Our findings were recently confirmed (40). Moreover, we have shown that the administration of the Sirt1 activator, SRT3025 reduced sclerostin in bone in mice in vivo (29), and in human femoral BMMSCs in vitro (41). In the current study we investigated the role of Sirtl in MAT, and discovered that it induces a thermogenic gene program, characteristic of brown adipocytes, in mouse and human BM-MSCs via PGC1 $\alpha$ stimulation and sclerostin inhibition.

\section{METHODS}

\section{Animals}

Sirt1 haplo-insufficient mice $\left(\operatorname{Sirt} 1^{\Delta /+}\right)$ lacking exon 4 of the Sirt1 gene and their wild type (WT) littermates of $129 / \mathrm{Sv}$ background were a generous gift (see Acknowledgments), and were used for this study (42). Adult 5-7-month-old inbred $\operatorname{Sirt} 1^{\Delta /+}$ and WT female and male mice were studied. Animals were housed under specific pathogen free (SPF) conditions with free access to water and chow \#2018 (Teklad Diets, Madison WI), containing $6.2 \%$ fat and energy density of $3.1 \mathrm{kCal} / \mathrm{gr}$. Daily food intake was determined for each mouse for 3 weeks between age 5 and 6 months. Fasting (overnight) glucose was determined in blood collected from the tail vein by an automatic glucometer (Accuchek; Roche Diagnostics GmbH, Mannheim, Germany). For Glucose Challenge Test (GCT) mice were fasted overnight. Glucose $2 \mathrm{~g} / \mathrm{kg}$ was injected intra-peritoneal, and blood was collected in $15 \mathrm{~min}$ intervals for $2 \mathrm{~h}$. Mice were sacrificed using isoflurane inhalation (Minrad INC, USA). Whole tibia with marrow and L3-L5 were removed, immediately frozen in liquid nitrogen and stored in $-80^{\circ} \mathrm{C}$ until analyzed. For bone fat volume determination tibiae were kept in $10 \%$ formalin for $48 \mathrm{~h}$ and then transferred to phosphate buffered saline (PBS) until 
analyzed. For bone histology tibiae were dehydrated in 50\% and then in $70 \% \mathrm{EtOH}$ and kept at $4^{\circ} \mathrm{C}$. All experiments were performed with the approval of the Animal Study Committee of the Hebrew University-Hadassah Medical School (MD-1213154-3).

\section{Determination of Bone Marrow Fat}

To determine tibiae bone marrow fat volume osmium tetroxide staining followed by micro-computed tomography $(\mu \mathrm{CT})$ analysis was performed in WT and $\operatorname{Sirt} 1^{\Delta /+}$ female mice, as previously described (43). Briefly, tibiae were fixed in $10 \%$ formalin, decalcified in $0.5 \mathrm{M}$ EDTA, soaked in a $1: 1$ solution of equal volumes of $2 \%$ aqueous osmium tetroxide $\left(\mathrm{O}_{\mathrm{s}} \mathrm{O}_{4}\right)$ and $5 \%$ potassium dichromate. The intact bones were scanned at $6 \mu \mathrm{m}$ resolution using micro-focus conebeam X-ray computed tomography ( $\mu$ CT40 Scanco Medical AG Brüttisellen, Switzerland). The scanner was operated at $55 \mathrm{KVp}, 144 \mu \mathrm{A}$, collecting 2,000 projections per rotation at $300 \mathrm{~ms}$ integration time. Total tibiae marrow fat volume as well as marrow fat volumes in the proximal and distal fourths were measured separately for each mouse. Histologic analysis was performed on $4 \mu \mathrm{m}$ thick decalcified tibial sections from the proximal tibiae and stained with hematoxylin. Adipocytes were identified as empty oval structures and were manually counted, as previously described (44). Bone marrow fat area was determined as the fraction of adipocyte area per total area. Images were obtained with a DS-Fi camera attached to an Eclipse 80i microscope (Nikon, USA), and analyzed with ImageJ (National Institutes of Health, USA, https://imagej.nih.gov/ij/).

\section{Primary Bone Marrow Cell Cultures}

Bone marrow cells were harvested from femurs and tibiae of 6 month-old Sirt $1^{\Delta /+}$ and WT female mice. The femurs and tibiae were removed and cleaned of connective tissue, the ends were cut, and the marrow was flushed with $\alpha$ $\mathrm{MEM} / 15 \%$ fetal bovine serum. Single-cell suspensions were prepared in $\alpha$-MEM by drawing the cells several times through graded needles. Cells collected from each mouse were plated in $100 \mathrm{~mm}$ plate. Non-adherent cells were removed after 3 days and the medium was changed every 3 days. Ten days later cells were harvested and plated in a density of $2 \times 10^{5}$ cells/well in six-well-plates. Adipogenesis was induced by $10 \mu \mathrm{g} / \mathrm{ml}$ insulin $/ 50 \mu \mathrm{M}$ dexamethasone $/ 100 \mu \mathrm{M}$ indomethacin $/ 500 \mu \mathrm{M}$ 3-isobutyl-1-methylxanthine administered on day 14 post plating at $70 \%$ confluence. RNA was isolated on day 3 post adipogenic induction.

\section{Experiments in the Murine Mesenchymal Stem-Cell Line C3H10T1/2}

The C3H10T1/2 (ATCC CCL-226) murine mesenchymal stem cell line is an established cell line model to investigate bone marrow adipocytes $(45,46)$. Sirt1 over-expressing C3H10T1/2 cells (Sirt1-OE) were previously generated and reported by us through stable retroviral infection with pBABE-Sirt1 (28). Adipogenesis was induced in C3H10T1/2 and in Sirt1-OE cells with $10 \mu \mathrm{g} / \mathrm{ml}$ insulin $/ 50 \mu \mathrm{M}$ dexamethasone/100 $\mu \mathrm{M}$ indomethacin/500 $\mu \mathrm{M}$ 3-isobutyl1-methylxanthine administered for 4 days followed by $10 \mu \mathrm{g} / \mathrm{ml}$ insulin $/ 50 \mu \mathrm{M}$ dexamethasone $/ 5 \mu \mathrm{M}$ rosiglitazone administration with medium changes twice a week (47). Protein was purified on day 7 post adipogenic induction. Adipogenesis was determined by oil-red-o staining on day 8-10 and was normalized to cell number determined by crystal violet staining $(28,48)$. In another set of experiments the Sirt1 activating compound SRT3025 $(29,49)$, kindly provided by SIRTRIS/GSK, was dissolved in dimethyl sulfoxide (DMSO) according to the manufacturer's instructions and was co-administered at a final concentration of $10 \mu \mathrm{M}$ with the adipogenic medium to $\mathrm{C} 3 \mathrm{H} 10 \mathrm{~T} 1 / 2$ cells. RNA was isolated on day 1 . Oil-red-o staining and protein purification were conducted as described above.

The Sirt1 inhibiting compound Ex527 (6-Chloro2,3,4,9-tetrahydro-1H-Carbazole-1-carboxamide; E7034, Sigma-Aldrich, Ukraine) $(29,50,51)$ was dissolved in dimethyl sulfoxide (DMSO) according to the manufacturer's instructions and was co-administered at a final concentration of $10 \mu \mathrm{M}$ with the adipogenic medium to $\mathrm{C} 3 \mathrm{H} 10 \mathrm{~T} 1 / 2$ cells. RNA purification was conducted as described above.

\section{Experiments in Human Bone Marrow Mesenchymal Stromal Cells}

Human bone marrow mesenchymal stromal cells (hBM-MSCs) have the capacity to spontaneously differentiate into adipocytes in ex vivo cell cultures without the addition of an adipogenic medium (52). Fresh femoral bone marrow was harvested during femoral canal preparation from three female patients (age 68 \pm 9.3 years) undergoing hip replacement for hip osteoarthritis or fractured head of femur $(n=4$, age $81 \pm 8.1)$, as part of an ongoing research project which was previously reported by us (41). None of the patients had diabetes or was treated with medications known to affect glucose, lipid or bone metabolism. The study was approved by the Hadassah-Hebrew University Medical Center ethics committee (HMO-0369-10), and informed consent was obtained from each patient prior to surgery. The bone marrow aspirate was collected in growing medium (GM) containing DMEM/5 mM glucose/10\%FBS/100 Units/ml penicillin $/ 100 \mathrm{mg} / \mathrm{ml}$ streptomycin sulfate $/ 0.25 \mathrm{mg} / \mathrm{ml}$ amphotericin B, treated with Lymphoprep \#1114544 (Ficoll, Axis-Shield PoC AS, Oslo, Norway), and centrifuged at $900 \mathrm{~g}$ for $30 \mathrm{~min}$. Cells at the intermediate interface were collected and centrifuged again at $900 \mathrm{~g}$ for $10 \mathrm{~min}$. The resulting mononuclear pellet was re-suspended in GM, plated at a density of $5 \times 10^{5}$ cells $/ 35 \mathrm{~mm}$ dish and cultured in GM with a medium change twice a week (53). The Sirt1 activator SRT3025 at concentration of $5 \mu \mathrm{M}$ or a vehicle was added upon confluence and with every medium change. RNA was collected 3 days following treatment initiation, while protein collection was carried out on day 10 .

\section{Gene Expression Analysis}

Whole tibiae and vertebrae with marrow, primary cultures of BMSCs, C3H10T1/2 cells and human BM-MSCs were homogenized in TRIzol (Invitrogen, Carlsbad CA). Total RNA was extracted, converted to cDNA using the qScript kit (Quanta BioSciences, Inc. Gaithersburg, MD, USA). Gene expression 
analysis was performed using SYBR Green-based real-timePCR (Kapa Syber, Kapa Biosystems (Pty) Ltd, Cape Town, South Africa). Supplementary Table 1 provides all of the primer sequences used in this study. Relative gene expression was determined by the comparative CT method with $\beta$ Actin and Polr $2 a$ as controls in murine and cell line experiments (geometric mean). $\beta$ Actin was used as control for analysis of experiments conducted in human BM-MSCs. For experiments conducted in $\mathrm{C} 3 \mathrm{H} 10 \mathrm{~T} 1 / 2$ cells gene expression was further normalized to the expression of Adipoq. For experiments conducted in human $\mathrm{BM}-\mathrm{MSCs}$ data was further normalized to $P P A R \gamma$ expression.

\section{Protein Analysis}

Protein was extracted in Laemmli buffer (2\% SDS/10\% glycerol/5\% 2-mercaptoethanol/ 0.01\% bromphenol blue/60 mM Tris $\mathrm{HCl}$ ). Antibodies for immunoblotting: Prdm16 (AbCam, ab106410), Pgc1 $\alpha$ (Cell Signaling, \#2178). $\alpha$-Tubulin (AbCam, ab106375). Glyceraldehyde-3-phosphate dehydrogenase (GAPDH, Abcam, ab8245).

\section{Statistical Analysis}

Results are presented as Mean \pm SEM. Data was analyzed by unpaired Student's $t$-test to compare group means. 1-way
ANOVA followed by Holm-Sidak's analysis was used to compare three groups. Analysis was performed using GraphPad (San Diego, CA, USA) Prism version 6.01. Each experiment was conducted in triplicates and was repeated at least 3 times. $P<$ 0.05 was considered statistically significant.

\section{RESULTS}

\section{Reduced Expression of Thermogenic Genes in MAT of Sirt1 ${ }^{\Delta /+}$ Female Mice}

Basal metabolic parameters including body weight, daily food intake, fasting glucose and the response to glucose load did not differ between WT and Sirt $1^{\Delta /+}$ mice of both genders (Supplementary Figures 1A-H). Previous work by others and us has demonstrated a sexual dimorphism with regard to the effects of Sirt1 deficiency in bone, showing a bone phenotype in female but not in male mice $(28,30,31)$. We therefore conducted most of our studies in female mice. Whole tibiae bone marrow fat volume determined by osmium staining was not different between WT and $\operatorname{Sirt}^{\Delta /+}$ female mice (Figure 1A). Proximal and distal tibial marrow fat volume also did not differ between WT and $\operatorname{Sirt} 1^{\Delta /+}$ mice. In agreement with these results, tibial marrow adipocyte number and area was
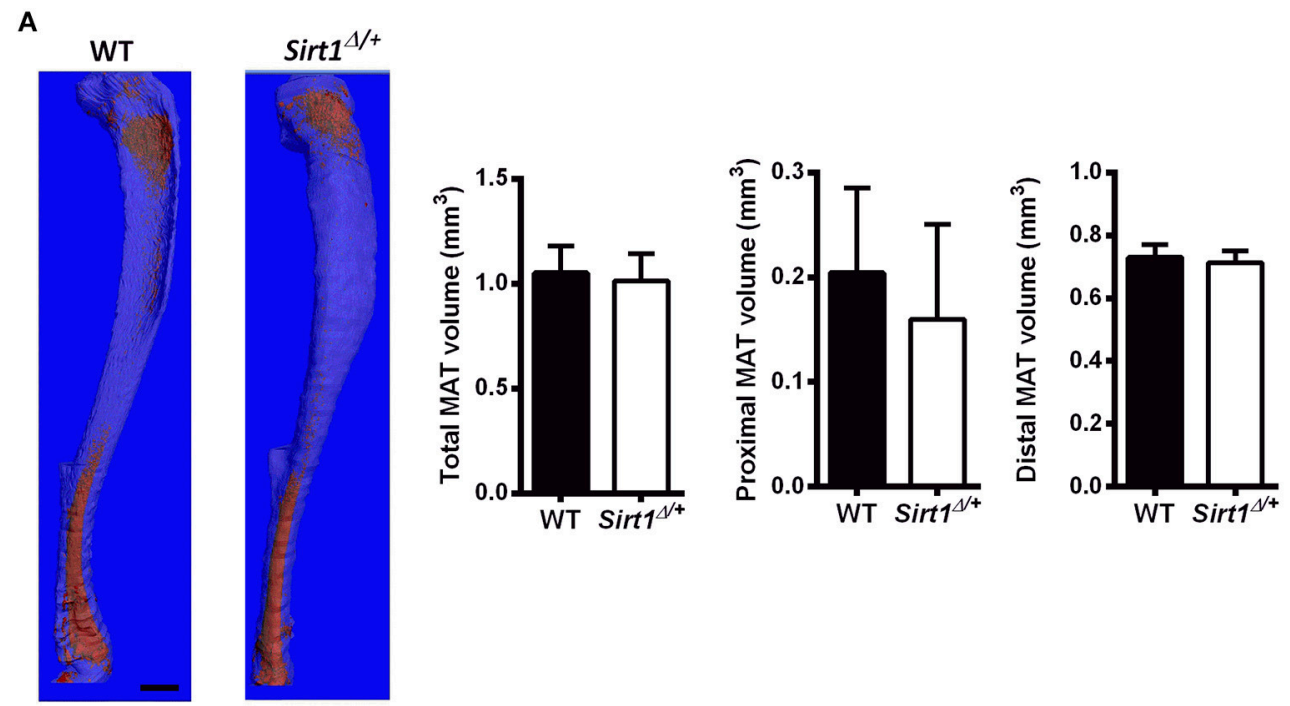

B
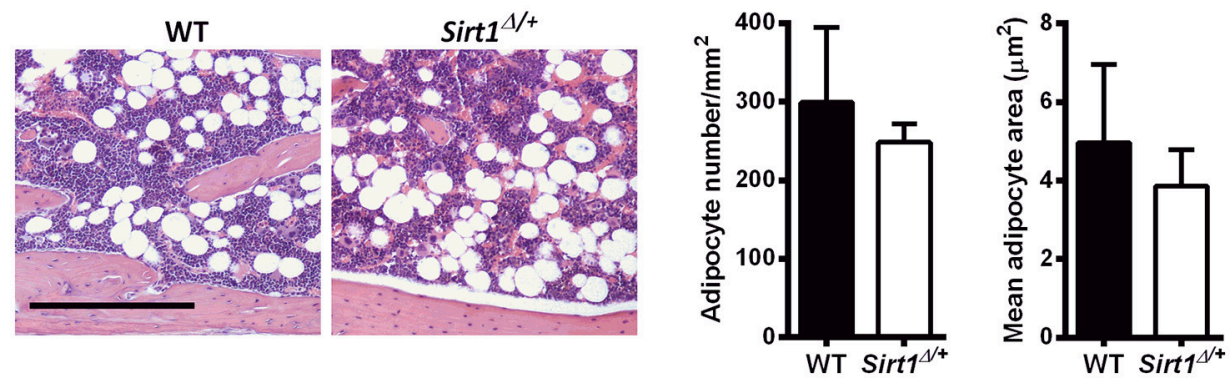

FIGURE 1 | Marrow adipose tissue (MAT) in Sirt ${ }^{\Delta /+}$ and WT female mice (A). Osmium tetroxide staining of tibiae followed by $\mu \mathrm{CT}$ analysis; A representative image (left) and quantification (right). Data is presented as fat volume. Scale bar $1 \mathrm{~mm}(n=8 \mathrm{mice} / \mathrm{group})$. (B) Hematoxylin-stained histological sections of proximal tibiae. Scale bar $200 \mu \mathrm{m} ;(n=3$ mice/group). Results are Mean \pm SEM. 
similar in WT and $\operatorname{Sirt}^{\Delta /}+$ female mice (Figure 1B). Strikingly, gene expression analysis in tibial MAT revealed a dramatic decrease of $\sim 50 \%$ in the thermogenic genes: $\beta 3 A R$, FoxC2, $\operatorname{Prdm16}, \operatorname{Pgcl} \alpha$, and Dio2 in Sirt $1^{\Delta /+}$ compared to WT female mice (Figure 2A). Importantly, Prdm16 and Pgc1 $\alpha$ mRNA expression was significantly decreased by over 2 fold in $\operatorname{Sirt} 1^{\Delta /+}$ compared to WT-derived primary BMSC cultures induced to adipogenesis (Figure 2B), indicating a cell autonomous effect of Sirt1 on the bone marrow adipocyte. No differences in tibial MAT gene expression were observed in $\operatorname{Sirt}^{\Delta /+}$ compared

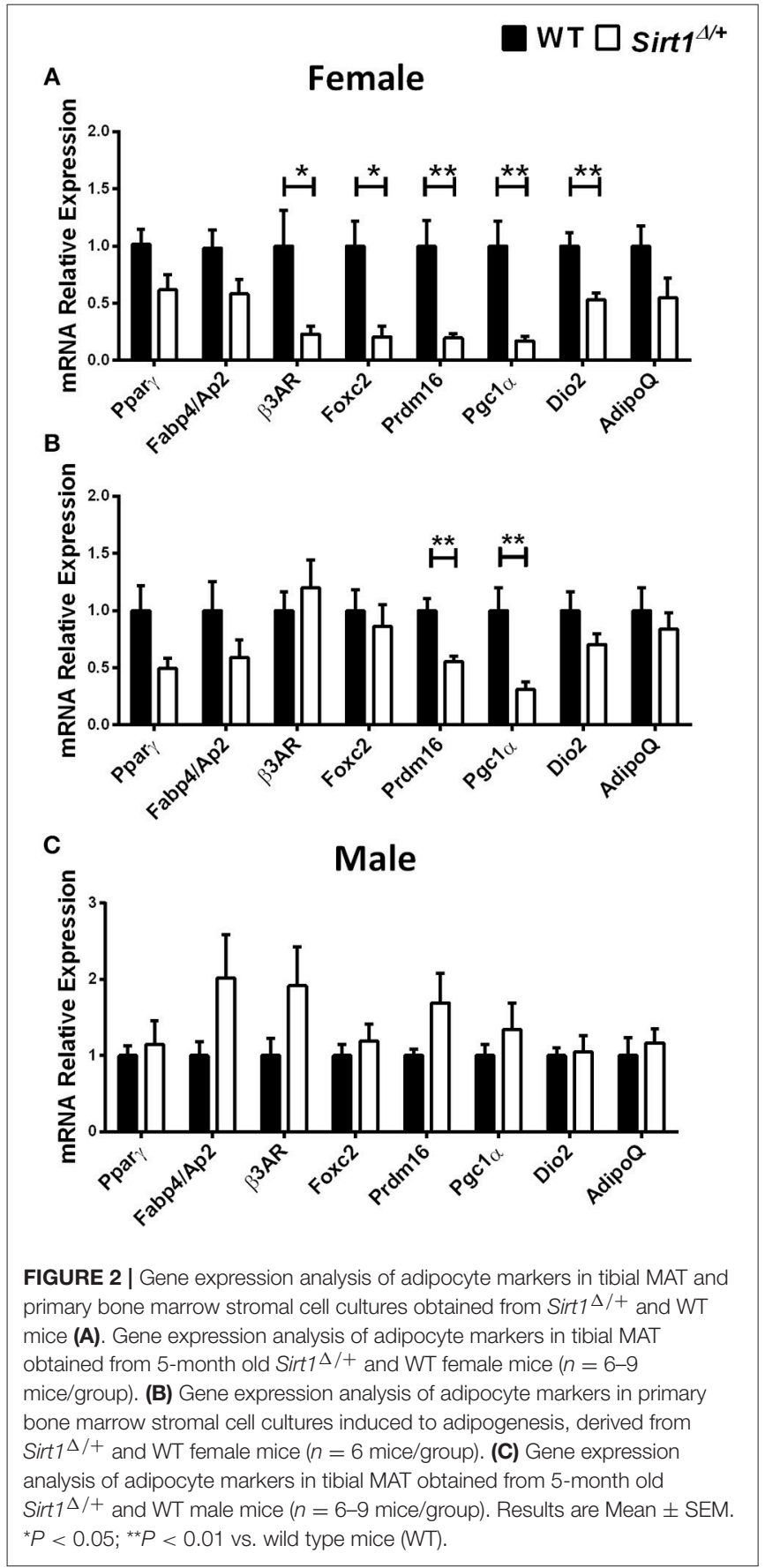

to WT male mice (Figure 2C). Thermogenic genes expression in vertebral MAT did not differ between genotypes in both genders (Figures 3A,B). Taken together, these results indicate that Sirt1 haplo-insufficiency leads to reduced thermogenic genes expression in tibial MAT in female mice.

We next asked if Sirt1 stimulation reciprocally increases the expression of a thermogenic genes program in BMSCs. To address this question three in vitro models were employed: (1) Sirt1 over-expressing C3H10T1/2 cells induced to adipogenesis. (2) Pharmacologic activation of Sirt1 by SRT3025 in C3H10T1/2 cells induced to adipogenesis. (3) Pharmacologic activation of Sirt1 in primary human femoral BM-MSCs.

\section{Increased Thermogenic Markers in Sirt1 Over-Expressing C3H10T1/2 cells}

Decreased lipid accumulation was observed in Sirt1 $O E$ compared to control $\mathrm{C} 3 \mathrm{H} 10 \mathrm{~T} 1 / 2$ cells induced to adipogenesis (Figure 4A). Elevated Prdm16 and Pgcl $\alpha$ protein level was observed in Sirt1 OE compared to control cells (Figures 4B,C). Consistent with these results, pharmacologic activation of Sirt1 by SRT3025 reduced the generation of white adipocytes and stimulated the expression of Pgc1 $\alpha$, Dio2, FoxC2, Tfam, and Cytochrome $C$ (Figures 5A-C). In contrast, Sirt1 inhibition by Ex527 significantly reduced the expression of Ucp1 (Figure 5D).

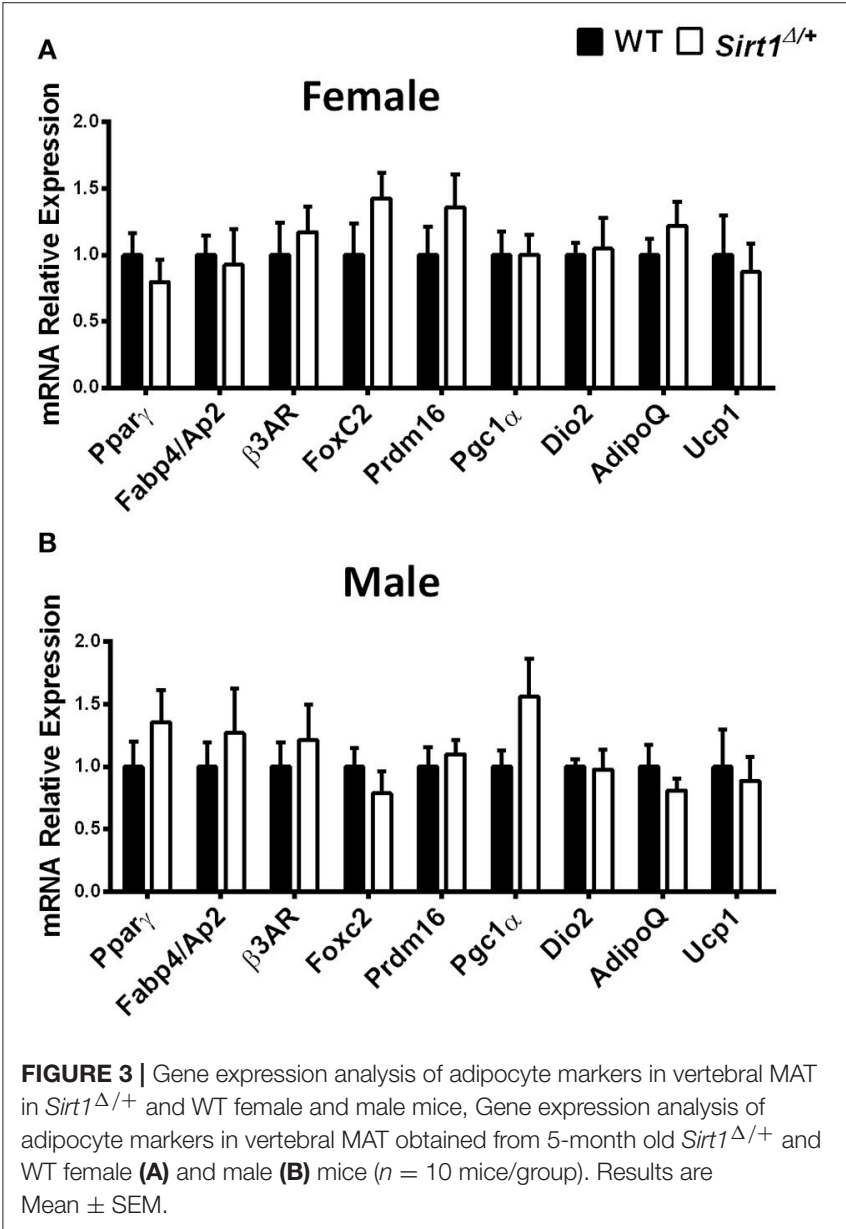


A

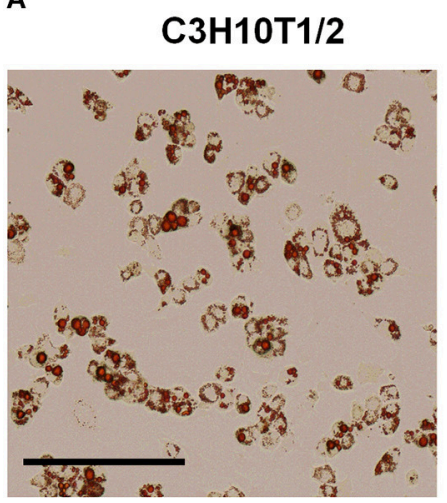

B

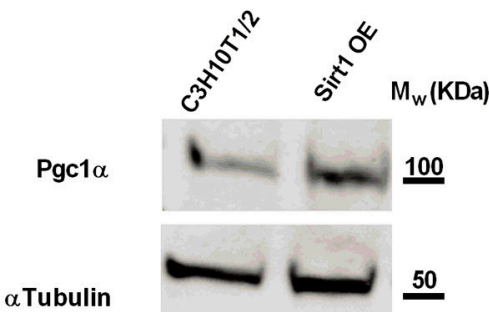

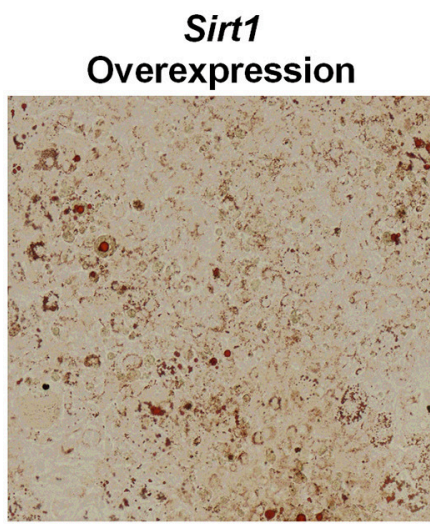

C

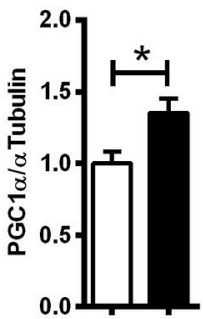

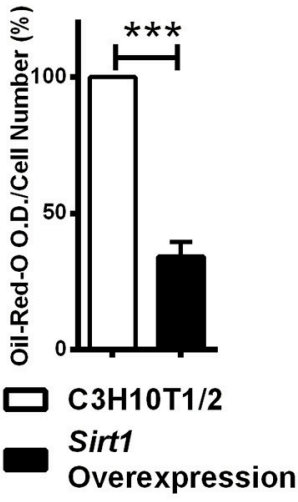

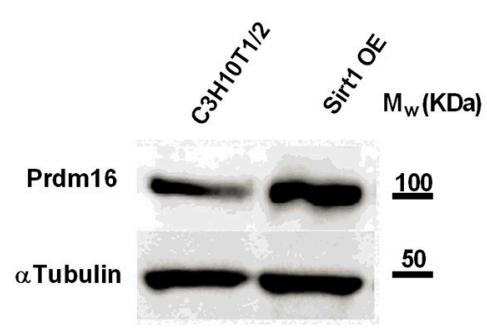

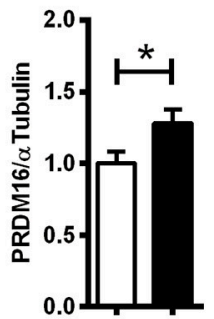

FIGURE 4 | The effect of Sirt1 over-expression on adipogenesis in C3HT101/2 cells (A). Oil-red-o staining in Sirt1 over-expressing (OE) and C3H10T1/2 cells induced to adipogenesis. Data is presented as optical density (OD) corrected for cell number (crystal violet staining). Scale bar 500 $\mu \mathrm{m}$. (B,C) Immunoblot of Pgc1 $\alpha$ and Prdm16 in Sirt1 OE and C3H10T1/2 cells 7 days post induction to adipogenesis. Results are Mean \pm SEM. ${ }^{*} P<0.05 ;{ }^{* \star *} P<0.001$ vs. C3HT101/2 cells.

\section{Sirt1 Activation by SRT3025 Promotes Thermogenic Genes Expression in Human BM-MSCs}

To investigate if the effects of Sirt1 on the marrow adipocyte phenotype can be extended to human BM-MSCs, SRT3025 was administered to primary human femoral BM-MSCs. Strikingly, SRT3025-treated human BM-MSCs had increased mRNA expression of PGC1 $\alpha$ (Figure 6A) accompanied by elevated PGC1 $\alpha$ protein level (Figure 6B), suggesting that Sirt1 activates PGC1 $\alpha$ in human femoral BM-MSCs.

\section{Blocking Sclerostin Induces a Thermogenic Gene Program in Human BM-MSCs}

We have previously shown that Sirt1 down-regulates sclersotin in mice and human BM-MSCs $(28,29,41)$. As sclersotin stimulates marrow adipogenesis (54), we hypothesized that blocking sclerostin will affect human bone marrow adipocyte gene expression profile.

Indeed, blocking sclerostin with the monoclonal antibody SclAbII $(55,56)$ induced a marked increase in gene expression of: $P R D M 16, \beta 3 A R, F O X C 2$, and importantly an over 2-fold increase in UCP1 expression, the hallmark of brown and beige adipocytes (Figure 6C). These effects were accompanied by a 2 -fold increase in PGC1 $\alpha$ protein level (Figure 6D). Taken together, this data indicate that blocking sclerostin stimulates a thermogenic genes signature in human femoral BM-MSCs.

\section{DISCUSSION}

This study reports for the first time a role for Sirt1 in MAT phenotype, demonstrating its stimulatory effect on a thermogenic gene program in marrow adipocytes. Sirt1 haploinsufficiency resulted in decreased expression of thermogenic gene markers in MAT in a gender- and site-specific manner. Reduced expression of $\beta 3 A R$, FoxC2, Prdm16, Pgc1 $\alpha$, and Dio2 was found in tibial but not in vertebral MAT derived from adult female but not male Sirt $1^{\Delta /+}$ mice. Similar effects were noted in primary BM-MSC cultures derived from $\operatorname{Sirt}^{\Delta /+}$ mice, indicating a cell autonomous effect of Sirt1 on the BM-MSC. In vitro, Sirt1 over-expression in $\mathrm{CH} 310 \mathrm{~T} 1 / 2$ cells increased the expression of thermogenic markers characteristic of brown adipocytes Prdm16 and Pgc1 $\alpha$, a mitochondrial biogenesis inducer, and a known Sirtl target (57). Importantly, in human femoral BM-MSCs pharmacologic Sirt1 activation and blocking its target, sclerostin, had a stimulatory effect on $\operatorname{Pgcl} \alpha$ protein level and thermogenic genes expression.

Sirt1 was previously shown to directly deacetylase Pgcl $\alpha$ in liver and muscle, thereby promoting its phosphorylation by 5' adenosine monophosphate-activated protein kinase (AMPK), resulting in its activation $(58,59)$. The current study demonstrates for the first time that Sirt1 upregulates Pgcl $\alpha$ in murine and human BM-MSCs. Pgcl $\alpha$ was reported to increase thermogenic genes expression in white subcutaneous adipocytes (60) and brown adipocytes (61). Furthermore, Pgcl $\alpha$ is a master 


\section{Growing Medium + Vehicle \\ $\square$ Adipogenic Medium + Vehicle \\ Adipogenic medium $+10 \mu \mathrm{M}$ SRT3025}

A
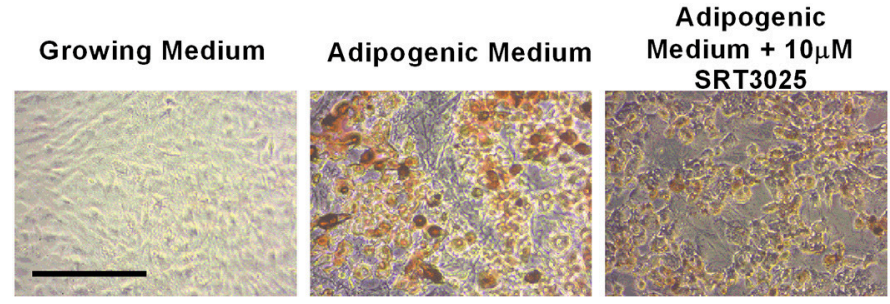

B

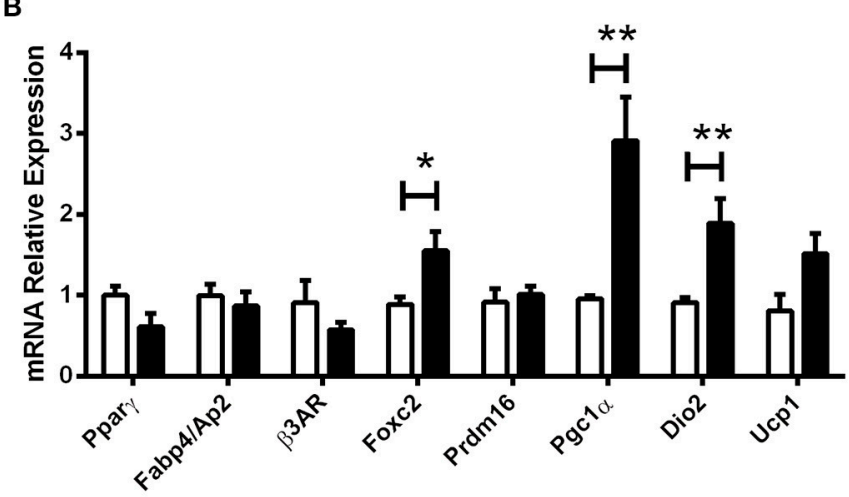

D

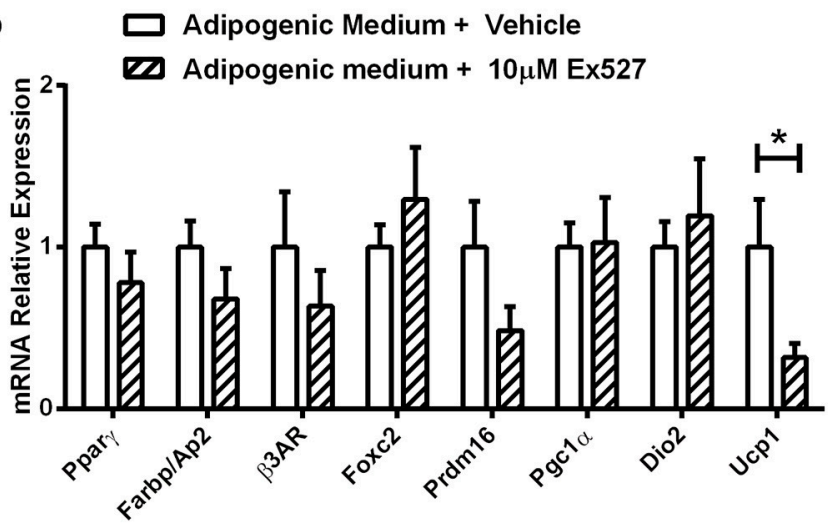

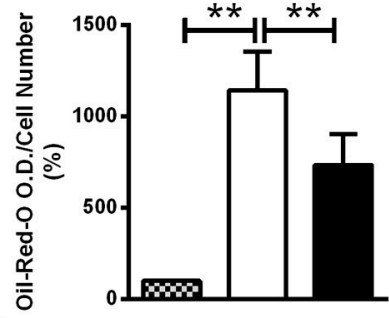

C

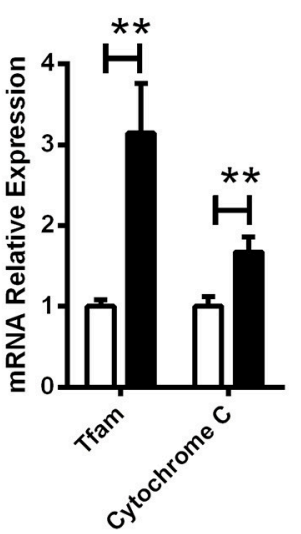

FIGURE 5 | The effects of Sirt1 pharmacologic activation and inhibition on adipogenic markers in C3HT101/2 cells (A). Oil-red-o staining in C3H10T1/2 cells induced to adipogenesis and supplemented with SRT3025 or vehicle (DMSO). (B,C) Gene expression analysis of adipocyte (B) and mitochondrial markers (C) induced to adipogenesis and supplemented with SRT3025 or vehicle (DMSO). (D) Gene expression analysis of adipocyte markers induced to adipogenesis and supplemented with Ex527 or vehicle (DMSO). Results are Mean \pm SEM. ${ }^{*} P<0.05 ;{ }^{* *} P<0.01$ vs. vehicle-treated C3HT101/2 cells.

mitochondrial regulator, stimulating mitochondrial biogenesis and inducing the expression of components of the mitochondrial respiratory chain. Indeed, in our study gene expression of Tfam, a marker of mitochondrial biogenesis, and Cytochrome $C$ was significantly increased with Sirt1 pharmacologic activation in vitro. The role of $\mathrm{Pgcl} \alpha$ in bone and BM-MSCs was only recently revealed. In vivo and in vitro gain and loss-of-function studies demonstrated that $\mathrm{Pgcl} \alpha$ regulates the skeletal stem cell fate, restraining marrow adipocyte differentiation and promoting osteogenesis (62). Our data indicate that Sirt1 stimulates Pgcl $\alpha$ expression in BM-MSCs thereby leading to induction of a thermogenic gene program.

Interestingly, Prdm 16 was also consistently influenced by Sirt 1 status in the various in vivo and in vitro models employed in this study. Prdm16 was significantly decreased in tibial MAT and in primary BM-MSC cultures derived from $\operatorname{Sirt}^{\Delta /+}$ compared to WT female mice. Along these lines, it was markedly increased with Sirt1 over-expression or activation in vitro. Prdm16 is an activator of $\operatorname{Pgcl} \alpha$ expression and transcriptional function through direct protein interaction. It also induces $\operatorname{Pgc1} \alpha, U c p 1$, 

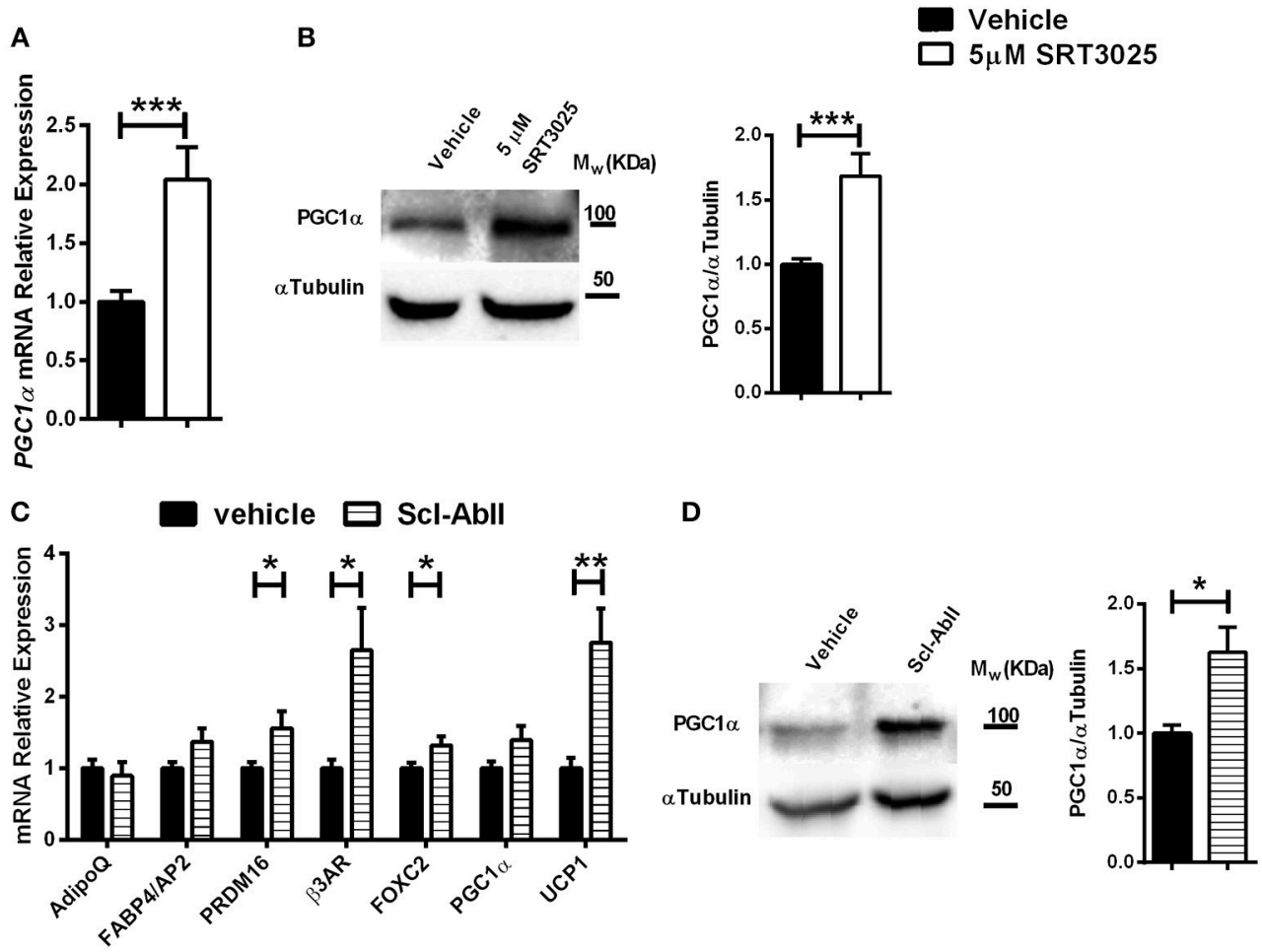

FIGURE 6 | The effects of SRT3025 and anti-Sclerostin antibody on adipogenic markers in human femoral bone marrow mesynchemal stem cells (hBM-MSCs) (A). Gene expression analysis of PGC1 $\alpha$ in SRT3025-treated hBM-MSCs. (B) Immunoblot of PGC1 $\alpha$. A representative image (left) and densitometry (right) with $\alpha$ Tubulin as control. (C) Gene expression analysis of thermogenic genes in anti-Sclerostin Abll treated hBM-MSCs (D). Immunoblot of PGC1 $\alpha$ in hBM-MSCs treated with anti-Sclerostin Abll. A representative image (left) and densitometry (right) with $\alpha$ Tubulin as control. Results are mean \pm SEM. ${ }^{\star} P<0.05$; ${ }^{\star \star} P<0.01 ;{ }^{* \star \star} P<0.001$ vs. vehicle-treated hBM-MSCs.

and Dio2 expression in adipocytes (63). However, regulation of Prdm16 by Sirt1 has not been described before. Only one study demonstrated that Sirt1-dependent Ppary deacetylation allows Prdm16 recruitment to Ppary thereby modulating its transcriptional activity, favoring BAT genes expression while repressing WAT genes (27). Thus, the underlying mechanisms governing the observed changes in Prdm16 in this study remain to be elucidated.

We have previously reported that Sirt1 down-regulates sclerostin by deacetylating histones 3 and 4 at its promoter, leading to inhibition of Sost gene expression (28). These results were recently confirmed by Stegen et al who demonstrated that conditional deletion of the oxygen sensor prolyl hydroxylase (PHD) 2 in osteocytes resulted in enhanced HIF-1 $\alpha$ signaling that stimulated Sirt1-dependent deacetylation of the Sost promoter and reduced sclerostin expression (40). Sclerostin, an inhibitor of the WNT/ $\beta$-catenin pathway, was reported to induce adipocyte differentiation in 3T3-L1 cells (64), primary murine BM-MSCs (54), and human BM-MSCs (54). Along these lines, lower levels of MAT were found in tibiae of sclerostin knockout (SOST-KO) mice, while sclerostin neutralization with a neutralizing antibody significantly decreased MAT (54). Our results demonstrate for the first time that blocking sclerostin with a neutralizing antibody, currently under advanced investigation for the treatment of osteoporosis, induces a thermogenic gene program in human BM-MSCs, and increases the expression of UCP1, a driver of mitochondrial heat generation and energy expenditure. UCP1, a protein located on the inner mitochondrial membrane, uncouples electron transport from adenosine triphosphate (ATP) generation. The resulting energy derived from substrate oxidation is dissipated as heat. UCP1 is expressed in brown and beige adipocytes. Some previous studies failed to detect it in MAT, while others reported low expression levels $(11,44)$. The metabolic significance of inducing UCP1 in MAT by blocking sclerostin remains to be investigated.

Differences in MAT phenotype between $\operatorname{Sirt} 1^{\Delta /+}$ and WT female mice were detected in tibiae but not in lumbar MAT. Lumbar vertebrae is a skeletal site in the mouse that has little MAT, whereas proximal tibial MAT was shown to be metabolically responsive to cold exposure (20). Caudal vertebrae was previously shown to have characteristics of constitutive MAT (cMAT) that contains large adipocytes and does not respond to systemic challenges. Thus, lack of difference in vertebral MAT phenotype is not surprising. Of note, most of the studies investigating murine MAT have used the $\mathrm{C} 57 \mathrm{BL} / 6 \mathrm{~J}$ and $\mathrm{C} 3 \mathrm{H} / \mathrm{HeJ}$ mouse strains, whereas data in $129 / \mathrm{Sv}$ used in this study, is lacking.

This study is not without its limitations. The physiologic significance of our findings could not be evaluated in the mouse model used in this study. Exposure of MSC-specific 
Sirt1 knock-out mice to cold temperature or a high fat diet could have provided insight into the contribution of MAT Sirt1 to local and whole body energy metabolism and needs to be performed in future studies. Secondly, gene expression analyses were performed in whole tibiae and vertebrae extracts similar to previously published studies $(4,65)$, and introduce the bias of contamination by other cell types. However, consistent results were obtained in primary BM-MSCs cultures derived from Sirt $1^{\Delta /+}$ and WT mice, supporting the notion of a direct cell autonomous effect of Sirt1 on the marrow adipocyte phenotype. Thirdly, we did not account for regional differences in tibial MAT composition, as was previously suggested (66). Finally, additional Sirt1 targets beyond Pgcl $\alpha$ and sclerostin may have played a role in driving a brown-like adipocyte gene expression program in BM-MSCs.

Whether inducing a thermogenic gene program in marrow adipocytes is beneficial to bone health, hematopoiesis local and whole body energy metabolism begs further investigation. Reduced MAT expression of brown adipocyte markers was previously reported in diabetic and aged mice, conditions associated with both increased skeletal fragility and impaired energy metabolism (44). Due to its wide favorable physiologic effects, Sirt1 has been considered an attractive therapeutic target for drug discovery. Sirtuin1 activating compounds (STACs) were generated, amongst them SRT3025, used in this study. SRT3025 was previously shown by us to restore bone mass and strength in OVX mice (29), but also to have off-target effects (67). In humans SRT3025 was shown to prolong QTc and its development was discontinued (68). As $\mathrm{NAD}^{+}$is an indispensable co-substrate required for Sirt1 and other sirtuins activity, there has been an increasing interest in small molecules that raise NAD+ levels as a mechanism to stimulate sirtuins activity (69).

In conclusion, this study shows that Sirt1 regulates the bone marrow adipocyte phenotype inducing a thermogenic gene program in mouse and human BM-MSCs. Inducing BAT-like features in subcutaneous and visceral fat depots is a much desired goal in combating obesity. Whether browning of MAT by Sirt 1 activation, sclerostin inhibition or other mechanisms is a plausible novel approach to serve this goal while improving skeletal health remains to be elucidated.

\section{ETHICS STATEMENT}

This study was carried out in accordance with the recommendations of IHC-GCP, Public Heath Regulation, the Governing regulations of Ministry of Health. The

\section{REFERENCES}

1. Cawthorn WP, Scheller EL, Learman BS, Parlee SD, Simon BR, Mori H. et al. Bone marrow adipose tissue is an endocrine organ that contributes to increased circulating adiponectin during caloric restriction. Cell Metab. (2014) 20:368-75. doi: 10.1016/j.cmet.2014.06.003

2. Bredella MA, Fazeli PK, Miller KK, Misra M, Torriani M, Thomas BJ, et al. Increased bone marrow fat in anorexia nervosa. J Clin Endocrinol Metab. (2009) 94:2129-36. doi: 10.1210/jc.2008-2532 protocol was approved by The Ethics (Helsinki) Committee at Hadassah University Hospital. All subjects gave written informed consent in accordance with the Declaration of Helsinki.

\section{AUTHOR CONTRIBUTIONS}

HA designed and performed most of the experiments and analyzed the data. IG designed and conducted some of the in vitro experiments. ME-H, LK, and OS were responsible for studies in humans. ME-H obtained the human samples and performed the experiments. RM and GK designed and conducted the marrow fat $\mu \mathrm{CT}$ quantification studies. GB performed experiments in murine BM-MSCs. EC-K designed and performed the experiments in human BM-MSCs. EA performed some in vitro experiments with SRT3025. RD-P conceived and designed the study, prepared the manuscript, and takes full responsibility for the work as a whole.

\section{FUNDING}

This study was funded by the Israel Science Foundation Grant $621 / 16$ (to RD-P) and the Joint Research Fund of the Hebrew University (to ME-H).

\section{ACKNOWLEDGMENTS}

We thank Frederick W. Alt of Harvard University for providing the $\operatorname{Sirt}^{\Delta /+}$ mice, SIRTRIS/GSK and Amgen for providing SRT3025 and Scl-AbII, respectively. We thank the late Raymond Kaplan and the Bnai Brith Leo Baeck London Lodge for their support of osteoporosis research. The osmium tetroxide staining was performed at the SCOPEM (Scientific Center for Optical and Electron Microscopy), ETH, Zurich. We thank Dr. Stephan Preibisch SCOPEM for his assistance.

\section{SUPPLEMENTARY MATERIAL}

The Supplementary Material for this article can be found online at: https://www.frontiersin.org/articles/10.3389/fendo. 2019.00126/full\#supplementary-material

Supplementary Figure 1 | Metabolic parameters in female and male $\operatorname{Sirt}_{1} \Delta /+$ and WT mice (A-D): females; (E-H): males. (A,E): Body weight. (B,F): Daily food intake. (C, G). Fasting blood glucose. (D,H). Glucose challenge test (GCT) Results are Mean \pm SEM ( $n=5-8$ mice/group).

Supplementary Table 1 | Mouse and human primer sequences.
3. Tencerova M, Figeac F, Ditzel N, Taipaleenmaki H, Nielsen TK, Kassem M. High-fat diet-induced obesity promotes expansion of bone marrow adipose tissue and impairs skeletal stem cell functions in mice. J Bone Miner Res. (2018) 33:1154-65. doi: 10.1002/ jbmr.3408

4. Styner M, Pagnotti GM, McGrath C, Wu X, Sen B, Uzer G, et al. Exercise decreases marrow adipose tissue through ss-oxidation in obese running mice. J Bone Miner Res. (2017) 32:1692-702. doi: 10.1002/ jbmr.3159 
5. Crossno JT Jr, Majka SM, Grazia T, Gill RG, Klemm DJ. Rosiglitazone promotes development of a novel adipocyte population from bone marrowderived circulating progenitor cells. J Clin Invest. (2006) 116:3220-8. doi: $10.1172 /$ JCI28510

6. Ryden M, Uzunel M, Hard JL, Borgstrom E, Mold JE, Arner E, et al. Transplanted bone marrow-derived cells contribute to human adipogenesis. Cell Metab. (2015) 22:408-17. doi: 10.1016/j.cmet.2015.06.011

7. Fazeli PK, Horowitz MC, MacDougald OA, Scheller EL, Rodeheffer MS, Rosen CJ, et al. Marrow fat and bone-new perspectives. J Clin Endocrinol Metab. (2013) 98:935-45. doi: 10.1210/jc.2012-3634

8. Rosen CJ, Bouxsein ML. Mechanisms of disease: is osteoporosis the obesity of bone? Nat Clin Pract Rheumatol. (2006) 2:35-43. doi: 10.1038/ncprheum0070

9. Scheller EL, Rosen CJ. What's the matter with MAT? marrow adipose tissue, metabolism, and skeletal health. Ann N Y Acad Sci. (2014) 1311:14-30. doi: $10.1111 /$ nyas. 12327

10. Georgiou KR, Hui SK, Xian CJ. Regulatory pathways associated with bone loss and bone marrow adiposity caused by aging, chemotherapy, glucocorticoid therapy and radiotherapy. Am J Stem Cells. (2012) 1:205-24.

11. Ambrosi TH, Scialdone A, Graja A, Gohlke S, Jank AM, Bocian C, et al. Adipocyte accumulation in the bone marrow during obesity and aging impairs stem cell-based hematopoietic and bone regeneration. Cell Stem Cell. (2017) 20:771-84 e6. doi: 10.1016/j.stem.2017.02.00

12. Naveiras O, Nardi V, Wenzel PL, Hauschka PV, Fahey F, Daley GQ. Bone-marrow adipocytes as negative regulators of the haematopoietic microenvironment. Nature. (2009) 460:259-63. doi: 10.1038/nature08099

13. Morris EV, Edwards CM. Bone marrow adipose tissue: a new player in cancer metastasis to bone. Front Endocrinol. 7:90. doi: 10.3389/fendo.2016.00090

14. Kajimura S, Spiegelman BM, Seale P. Brown and beige fat: physiological roles beyond heat generation. Cell Metab. (2015) 22:546-559. doi: 10.1016/j.cmet.2015.09.007

15. Bianco P, Robey PG. Skeletal stem cells. Development. (2015) 142:1023-7. doi: $10.1242 /$ dev. 102210

16. Bianco P, Cao X, Frenette PS, Mao JJ, Robey PG, Simmons PJ, et al. The meaning, the sense and the significance: translating the science of mesenchymal stem cells into medicine. Nat Med. (2013) 19:35-42. doi: $10.1038 / \mathrm{nm} .3028$

17. Zhou BO, Yue R, Murphy MM, Peyer JG, Morrison SJ. Leptin-receptorexpressing mesenchymal stromal cells represent the main source of bone formed by adult bone marrow. Cell Stem Cell. (2014) 15:154-68. doi: 10.1016/j.stem.2014.06.008

18. Yue R, Zhou BO, Shimada IS, Zhao Z, Morrison SJ. Leptin receptor promotes adipogenesis and reduces osteogenesis by regulating mesenchymal stromal cells in adult bone marrow. Cell Stem Cell. (2016) 18:782-96. doi: 10.1016/j.stem.2016.02.015

19. Fan Y, Hanai JI, Le PT, Bi R, Maridas D, DeMambro V, et al. Parathyroid hormone directs bone marrow mesenchymal cell fate. Cell Metab. (2017) 25:661-72. doi: 10.1016/j.cmet.2017.01.001

20. Scheller EL, Doucette CR, Learman BS, Cawthorn WP, Khandaker S, Schell B, et al. Region-specific variation in the properties of skeletal adipocytes reveals regulated and constitutive marrow adipose tissues. Nat Commun. (2015) 6:7808. doi: $10.1038 /$ ncomms 8808

21. Guarente L, Picard F. Calorie restriction-the SIR2 connection. Cell. (2005) 120:473-82. doi: 10.1016/j.cell.2005.01.029

22. Haigis MC, Guarente LP. Mammalian sirtuins-emerging roles in physiology, aging, and calorie restriction. Genes Dev. (2006) 20:2913-21. doi: $10.1101 / \operatorname{gad} .1467506$

23. Bordone L, Cohen D, Robinson A, Motta MC, van Veen E, Czopik A, et al. SIRT1 transgenic mice show phenotypes resembling calorie restriction. Aging Cell. (2007) 6:759-67. doi: 10.1111/j.1474-9726.2007.00335.x

24. Picard F, Kurtev M, Chung N, Topark-Ngarm A, Senawong T, Machado De Oliveira R, et al. Sirtl promotes fat mobilization in white adipocytes by repressing PPAR-gamma. Nature. (2004) 429:771-6. doi: 10.1038/nature02583

25. Xu C, Cai Y, Fan P, Bai B, Chen J, Deng HB, et al. Calorie restriction prevents metabolic aging caused by abnormal SIRT1 function in adipose tissues. Diabetes. (2015) 64:1576-90. doi: 10.2337/db14-1180

26. Hui X, Zhang M, Gu P, Li K, Gao Y, Wu D, et al. Adipocyte SIRT1 controls systemic insulin sensitivity by modulating macrophages in adipose tissue. EMBO Rep. (2017) 18:645-57. doi: 10.15252/embr.201643184
27. Qiang L, Wang L, Kon N, Zhao W, Lee S, Zhang Y, et al. Brown remodeling of white adipose tissue by SirT1-dependent deacetylation of Ppargamma. Cell. (2012) 150:620-32. doi: 10.1016/j.cell.2012.06.027

28. Cohen-Kfir E, Artsi H, Levin A, Abramowitz E, Bajayo A, Gurt I, et al. Sirt1 is a regulator of bone mass and a repressor of Sost encoding for sclerostin, a bone formation inhibitor. Endocrinology. (2011) 152:4514-24. doi: 10.1210/en.2011-1128

29. Artsi H, Cohen-Kfir E, Gurt I, Shahar R, Bajayo A, Kalish N, et al. The Sirtuin1 activator SRT3025 down-regulates sclerostin and rescues ovariectomy-induced bone loss and biomechanical deterioration in female mice. Endocrinology. (2014) 155:3508-15. doi: 10.1210/en.2014-1334

30. Edwards JR, Perrien DS, Fleming N, Nyman JS, Ono K, Connelly L, et al. Silent information regulator (Sir)T1 inhibits NF-kappaB signaling to maintain normal skeletal remodeling. J Bone Miner Res. (2013) 28:960-9. doi: $10.1002 /$ jbmr.1824

31. Iyer S, Han L, Bartell SM, Kim HN, Gubrij I, de Cabo R, et al. Sirtuin1 (Sirt1) promotes cortical bone formation by preventing beta-catenin sequestration by FoxO transcription factors in osteoblast progenitors. J Biol Chem. (2014) 289:9-78. doi: 10.1074/jbc.M114.56180

32. Zainabadi K, Liu CJ, Caldwell AL, Guarente L. SIRT1 is a positive regulator of in vivo bone mass and a therapeutic target for osteoporosis. PLoS ONE. (2017) 12:e0185236. doi: 10.1371/journal.pone.0185236

33. Zainabadi K, Liu CJ, Guarente L. SIRT1 is a positive regulator of the master osteoblast transcription factor, RUNX2. PLoS ONE. (2017) 12:e0178520. doi: 10.1371/journal.pone.0178520

34. Backesjo CM, Li Y, Lindgren U, Haldosen LA. Activation of Sirtl decreases adipocyte formation during osteoblast differentiation of mesenchymal stem cells. J Bone Miner Res. (2006) 21:993-1002. doi: 10.1359/jbmr.060415

35. Li Y, He X, Li Y, He J, Anderstam B, Andersson G, et al. Nicotinamide phosphoribosyltransferase (Nampt) affects the lineage fate determination of mesenchymal stem cells: a possible cause for reduced osteogenesis and increased adipogenesis in older individuals. J Bone Miner Res. (2011) 26:265664. doi: 10.1002/jbmr.480

36. Peltz L, Gomez J, Marquez M, Alencastro F, Atashpanjeh N, Quang $\mathrm{T}$, et al. Resveratrol exerts dosage and duration dependent effect on human mesenchymal stem cell development. PLoS ONE. (2012) 7:e37162. doi: 10.1371/journal.pone.0037162

37. Simic P, Zainabadi K, Bell E, Sykes DB, Saez B, Lotinun S, et al. SIRT1 regulates differentiation of mesenchymal stem cells by deacetylating betacatenin. EMBO Mol Med. (2013) 5:430-40. doi: 10.1002/emmm.201201606

38. Kennell JA, MacDougald OA. Wnt signaling inhibits adipogenesis through beta-catenin-dependent and -independent mechanisms. J Biol Chem. (2005) 280:24004-10. doi: 10.1074/jbc.M501080200

39. Qiu W, Andersen TE, Bollerslev J, Mandrup S, Abdallah BM, Kassem M. Patients with high bone mass phenotype exhibit enhanced osteoblast differentiation and inhibition of adipogenesis of human mesenchymal stem cells. J Bone Miner Res. (2007) 22:1720-31. doi: 10.1359/jbmr. 070721

40. Stegen S, Stockmans I, Moermans K, Thienpont B, Maxwell PH, Carmeliet $\mathrm{P}$, et al. Osteocytic oxygen sensing controls bone mass through epigenetic regulation of sclerostin. Nat Commun. (2018) 9:2557. doi: 10.1038/s41467-018-04679-7

41. El-Haj M, Gurt I, Cohen-Kfir E, Dixit V, Artsi H, Kandel L, et al. Reduced Sirtuin1 expression at the femoral neck in women who sustained an osteoporotic hip fracture. Osteoporos Int. (2016) 27:2373-8. doi: 10.1007/s00198-016-3536-4

42. Cheng HL, Mostoslavsky R, Saito S, Manis JP, Gu Y, Patel P, et al. Developmental defects and p53 hyperacetylation in Sir2 homolog (SIRT1)-deficient mice. Proc Natl Acad Sci USA. (2003) 100:10794-9. doi: $10.1073 /$ pnas. 1934713100

43. Clinthorne JF, Adams DJ, Fenton JI, Ritz BW, Gardner EM. Short-term refeeding of previously energy-restricted C57BL/6 male mice restores body weight and body fat and attenuates the decline in natural killer cell function after primary influenza infection. J Nutr. (2010) 140:1495-501. doi: 10.3945/jn. 110.122408

44. Krings A, Rahman S, Huang S, Lu Y, Czernik PJ, Lecka-Czernik B. Bone marrow fat has brown adipose tissue characteristics, which are attenuated with aging and diabetes. Bone. (2012) 50:546-52. doi: 10.1016/j.bone.2011.06.016 
45. Lee N, Kim I, Park S, Han D, Ha S, Kwon M, et al. Creatine inhibits adipogenesis by downregulating insulin-induced activation of the phosphatidylinositol 3-kinase signaling pathway. Stem Cells Dev. (2015) 24:983-94. doi: 10.1089/scd.2014.0130

46. Beg M, Chauhan P, Varshney S, Shankar K, Rajan S, Saini D, et al. A withanolide coagulin-L inhibits adipogenesis modulating Wnt/beta-catenin pathway and cell cycle in mitotic clonal expansion. Phytomedicine. (2014) 21:406-14. doi: 10.1016/j.phymed.2013.10.009

47. Moisan A, Rivera MN, Lotinun S, Akhavanfard S, Coffman EJ, Cook EB, et al. The WTX tumor suppressor regulates mesenchymal progenitor cell fate specification. Dev Cell. (2011) 20:583-96. doi: 10.1016/j.devcel.2011. 03.013

48. Scragg MA, Ferreira LR. Evaluation of different staining procedures for the quantification of fibroblasts cultured in 96-well plates. Anal Biochem. (1991) 198:80-5. doi: 10.1016/0003-2697(91)90509-R

49. Gilbert RE, Thai K, Advani SL, Cummins CL, Kepecs DM, Schroer SA, et al. SIRT1 activation ameliorates hyperglycaemia by inducing a torpor-like state in an obese mouse model of type 2 diabetes. Diabetologia. (2015) 58:819-27. doi: 10.1007/s00125-014-3485-4

50. Gertz M, Fischer F, Nguyen GT, Lakshminarasimhan M, Schutkowski M, Weyand M, et al. Ex-527 inhibits Sirtuins by exploiting their unique NAD+dependent deacetylation mechanism. Proc Natl Acad Sci USA. (2013) 110, E2772-81. doi: 10.1073/pnas.1303628110

51. Yang H, Yang T, Baur JA, Perez E, Matsui T, Carmona JJ, et al. Nutrientsensitive mitochondrial NAD+ levels dictate cell survival. Cell. (2007) 130:1095-107. doi: 10.1016/j.cell.2007.07.035

52. Amable PR, Teixeira MV, Carias RB, Granjeiro J, Borojevic R. Gene expression and protein secretion during human mesenchymal cell differentiation into adipogenic cells. BMC Cell Biol. (2014) 15:46. doi: 10.1186/s12860-014-0046-0

53. Mackay DL, Tesar PJ, Liang LN, Haynesworth SE. Characterizing medullary and human mesenchymal stem cell-derived adipocytes. J Cell Physiol. (2006) 207:722-8. doi: 10.1002/jcp.20617

54. Fairfield H, Falank C, Harris E, Demambro V, McDonald M, Pettitt JA, et al. The skeletal cell-derived molecule sclerostin drives bone marrow adipogenesis. J Cell Physiol. (2018) 233:1156-67. doi: 10.1002/jcp.25976

55. Li X, Ominsky MS, Warmington KS, Morony S, Gong J, Cao J, et al. Sclerostin antibody treatment increases bone formation, bone mass, and bone strength in a rat model of postmenopausal osteoporosis. J Bone Miner Res. (2009) 24:578-88. doi: 10.1359/jbmr.081206

56. Li X, Warmington KS, Niu QT, Asuncion FJ, Barrero M, Grisanti M, et al. Inhibition of sclerostin by monoclonal antibody increases bone formation, bone mass, and bone strength in aged male rats. J Bone Miner Res. (2010) 25:2647-56. doi: 10.1002/jbmr.182

57. Iwabu M, Yamauchi T, Okada-Iwabu M, Sato K, Nakagawa T, Funata M, et al. Adiponectin and AdipoR1 regulate PGC-1alpha and mitochondria by $\mathrm{Ca}(2+)$ and AMPK/SIRT1. Nature. (2010) 464:1313-9. doi: 10.1038/nature08991

58. Rodgers JT, Lerin C, Haas W, Gygi SP, Spiegelman BM, Puigserver P. Nutrient control of glucose homeostasis through a complex of PGC-1alpha and SIRT1. Nature. (2005) 434:113-8. doi: 10.1038/nature03354

59. Amat R, Planavila A, Chen SL, Iglesias R, Giralt M, Villarroya F. SIRT1 controls the transcription of the peroxisome proliferator-activated receptor-gamma co-activator-1alpha (PGC-1alpha) gene in skeletalmuscle through the PGC-1alpha autoregulatory loop and interaction with MyoD. J Biol Chem. (2009) 284:21872-880. doi: 10.1074/jbc.M109. 022749

60. Tiraby C, Tavernier G, Lefort C, Larrouy D, Bouillaud F, Ricquier D, et al. Acquirement of brown fat cell features by human white adipocytes. J Biol Chem. (2003) 278:33370-6. doi: 10.1074/jbc.M305235200

61. Uldry M, Yang W, St-Pierre J, Lin J, Seale P, Spiegelman BM. Complementary action of the PGC-1 coactivators in mitochondrial biogenesis and brown fat differentiation. Cell Metab. (2006) 3:333-41. doi: 10.1016/j.cmet.2006.04.002

62. Yu B, Huo L, Liu Y, Deng P, Szymanski J, Li J, et al. PGC-1alpha controls skeletal stem cell fate and bone-fat balance in osteoporosis and skeletal aging by inducing TAZ. Cell Stem Cell. (2018) 23:193-209.e5. doi: 10.1016/j.stem.2018.09.001

63. Seale P, Kajimura S, Yang W, Chin S, Rohas LM, Uldry M, et al. Transcriptional control of brown fat determination by PRDM16. Cell Metab. (2007) 6:38-54. doi: 10.1016/j.cmet.2007.06.001

64. Ukita M, Yamaguchi T, Ohata N, Tamura M. Sclerostin enhances adipocyte differentiation in 3T3-L1 cells. J Cell Biochem. (2016) 117:1419-28. doi: $10.1002 /$ jcb.25432

65. Styner M, Pagnotti GM, Galior K, Wu X, Thompson WR, et al. Exercise regulation of marrow fat in the setting of PPARgamma agonist treatment in female C57BL/6 mice. Endocrinology. (2015) 156:2753-61. doi: 10.1210/en.2015-1213

66. Lecka-Czernik B, Stechschulte LA, Czernik PJ, Sherman SB, Huang S, Krings A. Marrow adipose tissue: skeletal location, sexual dimorphism, and response to sex steroid deficiency. Front Endocrinol. (2017) 8:188. doi: $10.3389 /$ fendo.2017.00188

67. Gurt I, Artsi H, Cohen-Kfir E, Hamdani G, Ben-Shalom G, Feinstein B, et al. The Sirtl activators SRT2183 and SRT3025 inhibit RANKLinduced osteoclastogenesis in bone marrow-derived macrophages and down-regulate Sirt3 in Sirt1 null cells. PLoS ONE. (2015) 10:e134391. doi: 10.1371/journal.pone.0134391

68. Dai H, Sinclair DA, Ellis JL, Steegborn C. Sirtuin activators and inhibitors: promises, achievements, and challenges. Pharmacol Ther. (2018) 188:140-54. doi: 10.1016/j.pharmthera.2018.03.004

69. Martens CR, Denman BA, Mazzo MR, Armstrong ML, Reisdorph N, McQueen MB, et al. Chronic nicotinamide riboside supplementation is welltolerated and elevates $\mathrm{NAD}(+)$ in healthy middle-aged and older adults. Nat Commun. (2018) 9:1286. doi: 10.1038/s41467-018-03421-7

Conflict of Interest Statement: The authors declare that the research was conducted in the absence of any commercial or financial relationships that could be construed as a potential conflict of interest.

Copyright (c) 2019 Artsi, Gurt, El-Haj, Müller, Kuhn, Ben Shalom, Cohen-Kfir, Abramowitz, Kandel, Safran and Dresner-Pollak. This is an open-access article distributed under the terms of the Creative Commons Attribution License (CC BY). The use, distribution or reproduction in other forums is permitted, provided the original author(s) and the copyright owner(s) are credited and that the original publication in this journal is cited, in accordance with accepted academic practice. No use, distribution or reproduction is permitted which does not comply with these terms. 